\title{
General
}

\section{Zolpidem: Efficacy and Side Effects for Insomnia}

Amber N. Edinoff, MD ${ }^{1}{ }^{\circ}{ }^{a}$, Natalie Wu, MD1, Yahya T. Ghaffar, BS², Rosemary Prejean, BS², Rachel Gremillion, BS², Mark Cogburn, PhD', Azem A. Chami, MD³, Adam M. Kaye, PharmD ${ }^{4}$, Alan D. Kaye, MD, PhD ${ }^{3}$

1 Department of Psychiatry and Behavioral Medicine, Louisiana State University Health Shreveport, ${ }^{2}$ School of Medicine, Louisiana State University Health Shreveport, ${ }^{3}$ Department of Anesthesiology, Louisiana State University Health Shreveport, ${ }^{4}$ Department of Pharmacy Practice, Thomas J. Long School of Pharmacy and Health Sciences, University of the Pacific

Keywords: adverse effects, insomnia, z-drugs, zolpidem

https://doi.org/10.52965/001c.24927

\section{Health Psychology Research}

Vol. 9, Issue 1, 2021

\section{Purpose of Review}

Insomnia is a common type of sleep disorder defined by an ongoing difficulty initiating or maintaining sleep or nonrestorative sleep with subsequent daytime impairment. The sleep disturbances in insomnia usually manifest as difficulty in falling asleep, maintaining the continuity of sleep, or waking up too early in the morning well before the desired time, irrespective of the adequate circumstances to sleep every night. Insomnia can significantly impact daytime functioning resulting in decreased workplace productivity, proneness to errors and accidents, inability to concentrate, frequent daytime naps, and poor quality of life.

The treatment of insomnia should involve a multi-disciplinary approach, focusing on implementing behavioral interventions, improving sleep hygiene, managing psychological stressors, hypnotic treatment, and pharmacological therapy. The most effective therapies utilize cognitive behavioral therapy in conjunction with pharmacotherapy to minimize the needed dose and any resulting side effects. Non-benzodiazepine hypnotics such as zolpidem, eszopiclone, zaleplon are the most used as adjunctive treatment. One of the most used of these hypnotics is zolpidem. However, zolpidem has a wide variety of adverse effects and has some special considerations noted in the literature.

\section{Recent Findings}

Zolpidem has been associated with an increased risk of falls in hospitalized patients with an OR of 4.28 ( $\mathrm{P}<0.001)$ when prescribed short-term for insomnia. The relative risk (RR) for hip fractures in patients taking zolpidem was described as 1.92 (95\% CI 1.65-2.24; $\mathrm{P}<0.001$ ), with hip fractures being the most commonly seen. A case series of 119 inpatients aged 50 or older demonstrated that a majority (80.8\%) of ADRs were central nervous system (CNS)-related such as confusion, dizziness, and daytime sleepiness. A systematic review of 24 previous studies of sleepwalking associated with zolpidem demonstrated that the association was not dependent on age, dose, medical history, or even a history of sleepwalking at any time before zolpidem use. Suicide attempts and completion have been successfully linked with zolpidem use (OR 2.08; 95\% CI 1.83-2.63) in patients regardless of the presence of comorbid psychiatric illness. There have been multiple cases reported of seizures following the withdrawal of zolpidem. Most cases have demonstrated that withdrawal seizures occurred in patients taking daily dosages of around $450-600 \mathrm{mg} /$ day, but some reported them as low as $160 \mathrm{mg} / \mathrm{day}$. Rebound insomnia has been a concern to prescribers of zolpidem. Sleep onset latency has been demonstrated

\footnotetext{
Corresponding author:

Amber Edinoff, MD

Louisiana State University Health Science Center Shreveport

Department of Psychiatry and Behavioral medicine

1501 Kings Hwy

Shreveport, LA 71103

Phone: (318) 675-8969

aedino@lsuhsc.edu
} 
to be significantly increased on the first night after stopping zolpidem (13.0 minutes; 95\% CI $4.3-21.7 ; \mathrm{P}<0.01)$. Women had a non-significantly higher mean plasma concentration than men after 8 hours for the $10 \mathrm{mg}$ IR ( $28 \mathrm{vs.} 20 \mathrm{ng} / \mathrm{mL}$ ) and the $12.5 \mathrm{mg}$ MR (33 vs. 28ng/ $\mathrm{mL}$ ). The FDA has classified zolpidem as a category $\mathrm{C}$ drug based on adverse outcomes seen in animal fetal development. In the mothers exposed to zolpidem, there was an increased incidence of low birth weight $(\mathrm{OR}=1.39$; $\mathrm{P}<0.001)$, preterm delivery (OR 1.49; $\mathrm{P}<0.001)$, small for gestational age (SGA) babies $(\mathrm{OR}=1.34 ; \mathrm{P}<0.001)$, and cesarean deliveries $(\mathrm{OR}=1.74 ; \mathrm{P}<0.001)$. The rate of congenital abnormalities was not significantly increased with zolpidem ( 0.48 vs $0.65 \% ; \mathrm{P}=0.329)$.

\section{Summary}

Insomnia is linked to fatigue, distractibility, mood instability, decreased satisfaction, and overall decreased quality of life. Optimal therapy can aid patients in returning to baseline and increase their quality of life. Zolpidem is a helpful drug for the treatment of insomnia in conjunction with cognitive-behavioral therapy. When prescribed to elderly patients, the dose should be adjusted to account for their slower drug metabolism. Still, zolpidem is considered a reasonable choice of therapy because it has a lower incidence of residual daytime sleepiness and risk of falls when compared to other drugs. The most concerning adverse effects, which are often the most publicized, include the complex behaviors that have been seen in patients taking Zolpidem, such as sleeping, hallucinations, increased suicidality, driving cars while asleep, and even a few cases of committing homicide. Even so, zolpidem could be a suitable pharmacological treatment for insomnia. Decisions for whether or not to prescribe it and the dosage should be made on a case-by-case basis, considering both the psychical and psychiatric risks posed to the patient with insomnia versus if the patient were to take zolpidem to treat their condition.

\section{INTRODUCTION}

Insomnia is a common type of sleep disorder that is defined by an ongoing difficulty initiating or maintaining sleep or nonrestorative sleep with subsequent daytime impairment. 1 "Insomnia" generally refers to chronic insomnia, characterized by symptoms persisting for greater than one month with associated daytime dysfunction. Diagnosis is made by taking a thorough history, including sleep, medical, psychiatric, and substance use elements. Patients should be evaluated for comorbid conditions that could cause insomnia or complicate treatment. Symptoms of insomnia appear in up to $50 \%$ of adult populations, with $10-15 \%$ of individuals having severe symptoms that cause distress or impairment, meeting criteria for insomnia disorder. Risk factors include increasing age, female sex, comorbid medical conditions, shift work, and possibly low socioeconomic status and unemployment. ${ }^{2}$ This disorder is of particular concern in the elderly population, with up to $50 \%$ of older adults (age 65 or older) complaining of difficulty initiating or maintaining sleep and 12 to $20 \%$ meeting criteria for diagnosis with insomnia disorder. Difficulty maintaining sleep is the most common complaint (50-70\%), and only about $50 \%$ of patients will experience remission during the follow-up period. ${ }^{3}$ The treatment of insomnia should be a multi-disciplinary approach, focusing on implementing behavioral interventions, improving sleep hygiene, managing psychological stressors, hypnotic treatment, and pharmacological therapy. The most effective therapies utilize cognitive behavioral therapy in conjunction with pharmacotherapy to minimize the needed dose and any resulting side effects. The preferred first-line treatments include short or intermediate-acting benzodiazepine receptor antagonists, ramelteon, sedating antidepressants, or other sedating agents such as anti-epileptic drugs and atypical an- tipsychotics. Over-the-counter therapies such as antihistamines, melatonin, or herbal/nutritional supplements are not recommended to treat chronic insomnia due to lack of efficacy. Barbiturates and barbiturate-type drugs, though previously used as a treatment for insomnia, are also no longer recommended. When initiating pharmacologic therapy, patients should be engaged in discussion about treatment goals, safety profiles of the drug, potential side effects and drug interactions, alternate treatments, and rebound insomnia. Long term medical therapy should be monitored with careful follow-up for assessment of efficacy, the appearance of adverse effects, and evaluation for onset or worsening of comorbid conditions. ${ }^{2}$

\section{INSOMNIA OVERVIEW}

According to DSM-V criteria, chronic insomnia is defined as individuals having difficulties in falling and maintaining sleep. ${ }^{4}$ Symptoms such as early morning awakening and occurrences of fatigue, attention deficits, and mood instability throughout the day are also frequently reported. ${ }^{5}$ Such symptoms need to persist for at least three months and cause significant distress before a diagnosis can be confirmed. ${ }^{4}$ The sleep disturbances in insomnia usually manifest as difficulty in falling asleep, maintaining the continuity of sleep (waking up in the middle of the night and difficulty in returning to sleep), or waking up too early in the morning well before the desired time, irrespective of the adequate circumstances to sleep every night. ${ }^{6}$ Insomnia can significantly impact daytime functioning resulting in decreased workplace productivity, proneness to errors and accidents, inability to concentrate, frequent daytime naps, and poor quality of life. ${ }^{6}$ Presentation is slightly different in children and is frequently reported with symptoms including awakening at night, resisting going to bed and sleeping 
independently, and unable to sleep without proper stimulations. ${ }^{6}$ Insomnia can affect their school performance, daily activity of playing, inability to concentrate and cause behavior problems. ${ }^{6}$

\section{PATHOPHYSIOLOGY}

The genes associated with insomnia include Apolipoprotein (Apo) E4, PER3 (Period Circadian Regulator 3), Clock (Clock Circadian Regulator), and 5-HTTLPR (Serotonin Transporter Linked Polymorphic Region), with a close association between insomnia and HLA-DQB1*0602 also being reported. ${ }^{6}$ The molecular factors responsible for regulating the sleep-wake cycle include chemicals like orexin, norepinephrine, and histamine that promote the aroused state, whereas chemicals like GABA (Gamma Amino Butyric Acid), adenosine, melatonin, and prostaglandin D2 promoting sleep. ${ }^{6}$ The orexin mediated increased neuronal firing in the wake-promoting areas (tuberomammillary nucleus, dorsal raphe, and locus coeruleus) and inhibition of the sleeppromoting areas (ventrolateral preoptic nucleus and median preoptic nucleus) is one of the possible mechanisms contributing to insomnia which is termed the sleep switch model. ${ }^{6}$ Investigations of the central and autonomous nervous systems have identified the genetic explanation of insomnia etiology by suggesting an imbalance between sleepwake cycles as the final common pathway related to the pathophysiology of chronic insomnia. ${ }^{4}$ The sleep-wake cycles are disrupted due to either the arousal systems being overactive, the sleep-inducing systems being hypoactive, or both. ${ }^{4}$ It is important to note that basic sleep-wake regulation is not disturbed in patients with chronic insomnia. Instead, these patients experience a hybrid or mixed-state sleep with ongoing signs of increased arousal, as suggested by fine-grained analysis of the sleep EEG in these patients. ${ }^{4}$ Therefore, chronic insomnia is an imbalance in the sleepwake switch with frequent shifting to the waking state during sleep.

\section{RISK FACTORS}

Risk factors associated with the development of chronic insomnia include exposure to psychosocial factors such as stress and predisposition to certain personality traits such as excessive worrying, repressed personality, perfectionism, and neuroticism. ${ }^{6}$ It is not uncommon to find patients with chronic insomnia also suffering from other psychiatric comorbidities such as mood and anxiety disorders. ${ }^{6}$ Risk factors can be slightly different for children, as children diagnosed with chronic insomnia often have a history of delayed milestones, hyperactive behavior, and separation anxiety. ${ }^{6}$ Increased use of alcohol and abuse/dependence on tobacco drugs and excessive caffeine intake have also been shown to affect the sleep-wake cycle. ${ }^{6,7}$

\section{EPIDEMIOLOGY}

Based on the criteria defined by the DSM-V for a diagnosis of chronic insomnia, it has been estimated that the prevalence of this disorder is about $6 \%$ in the general population. ${ }^{8}$ However, at least one-third of the general population presents with at least one symptom of chronic insomnia. ${ }^{7}$ If daytime symptoms and sleep dissatisfaction associated with insomnia are taken into account, the prevalence increases to about $20 \%{ }^{7}$ It is essential that such distinction be made because individuals who reported daytime symptoms and sleep dissatisfaction appeared to be more significant healthcare consumers and presented with more mental disorders. ${ }^{7}$ Chronic insomnia has higher prevalence rates in women than men, with the prevalence of insomnia symptoms generally increasing with age. ${ }^{7}$ Numerous factors such as lifestyle, use of psychoactive substances, and sleep disorders have been shown to initiate or maintain insomnia; however, the most frequently studied are mental illnesses and organic diseases. ${ }^{7}$ A strong association between insomnia and major depressive episodes has been constantly reported in the literature. Epidemiological genetic links of insomnia are yet to be studied. ${ }^{7}$

\section{CURRENT TREATMENT OF INSOMNIA}

\section{INITIAL NON-PHARMACOLOGIC APPROACHES}

The initial approach to chronic insomnia involves behavioral interventions targeted at improving sleep hygiene. Physicians should encourage regular exercise in young adults with insomnia. It has been linked to an increase in slow-wave sleep, less waking after sleep onset (WASO), and shorter sleep onset latency (SOL). ${ }^{9,10}$ Patients should be counseled on preventing the use of caffeine, nicotine, and alcohol beginning six hours before bedtime. Large meals and significant fluid intake in the evening should also be prevented. In addition, it is essential for those with chronic insomnia to maintain a consistent sleep-wake cycle with circumvention of daytime napping; this is referred to as temporal control therapy. ${ }^{9,11}$ Stimulus control therapy can be used to help the patient associate the bedroom with sleep and is characterized by lying down only when ready to sleep, getting out of bed after 20 minutes of lying down if unable to fall asleep, using the bed strictly for sleep and sex, and waking at a similar time each day regardless of the time of sleep onset. Patients without a history of bipolar disorder or epilepsy who spend prolonged times in bed trying to fall asleep may benefit from sleep restriction therapy (minimum of five hours) until homeostatic sleep drive increases and improve sleep efficiency. ${ }^{9,10}$

\section{COGNITIVE BEHAVIORAL THERAPY FOR INSOMNIA}

After failing one of the initial approaches, cognitive behavioral therapy for insomnia (CBT-I) aimed at changing the patient's misconceptions, beliefs, and attitudes towards sleep is the first-line option due to its high efficacy and lasting benefits in sleep quality. ${ }^{9,10,12}$ These effects have been demonstrated in numerous randomized control trials (RCTs) using polysomnography, neuropsychologic testing, home sleep monitoring, and subjective measures. ${ }^{13-17} \mathrm{Ob}$ jective measures consistently showed that CBT-I increases N2, N3, and REM stages of sleep, while simultaneously decreasing stage $\mathrm{N} 1$ and wakefulness. ${ }^{10}$ A systematic review 
of 20 independent studies with a combined total of 1,162 patients revealed SOL improved by 19.03 minutes (95\% CI, 14.12-23.93 min.), WASO improved by 26.00 minutes (CI 15.48-36.52 $\mathrm{min}$.), and sleep efficiency improved by $9.91 \%$ (CI 8.09-11.73\%). ${ }^{12}$

CBT-I is the combination of cognitive reconstruction with sleep hygiene interventions, stimulus control therapy, sleep restriction therapy, and, at times, relaxation therapy. ${ }^{10}$ Relaxation techniques reduce somatic tension by hypnosis, meditation, yoga, and progressive muscle relaxation. Autogenic training, the imagination of a calm environment with comforting bodily perceptions such as warmth and heaviness, can be combined with imagery training and other techniques used for relaxation. In addition, the patient can learn to control physiologic factors such as muscle tension via visual and auditory biofeedback therapy. ${ }^{9}$ CBT-I can also be used to aid in hypnotic discontinuation. ${ }^{18}$

\section{NON-BENZODIAZEPINE HYPNOTICS}

Certain medications can be used to augment nonpharmacologic interventions to treat insomnia, with the non-benzodiazepine hypnotics (sometimes called z-drugs) being the most commonly used by physicians. These drugs work at the alpha-1 subunit of the gamma-aminobutyric acid $A$ (GABA-A) receptor to exert their hypnotic effects by neuronal inhibition similar to benzodiazepines. RCTs have demonstrated that these drugs significantly decreased sleep latency compared to placebo by an average of 20 minutes $(\mathrm{P}<0.0001)$ and sustained those results long-term. ${ }^{11,19}$ Zolpidem immediate release is superior at reducing sleep latency and increasing TST out of all the z-drugs, making it a frequent first choice medication in this group. Zolpidem extended-release does not offer any additional benefit for treating insomnia but may increase the risk of next-day impairment. ${ }^{11}$ Sublingual zolpidem is faster acting and more effective at SOL reduction than the oral formulation. ${ }^{10} \mathrm{Al}$ ternatively, zaleplon has a shorter half-life. It can be used for patients who want to take a medication upon nighttime awakening rather than sleep maintenance before sleep onset. Eszopiclone has a longer half-life and is frequently associated with subsequent day impairment, making it the least favorable of the group. ${ }^{11}$

\section{ANTIDEPRESSANTS}

Many patients with mood disorders experience insomnia, and an antidepressant can be a valid option for some patients in combination with cognitive-behavioral therapy. ${ }^{11}$ Doxepin, a histamine $\mathrm{H}_{1}$ receptor antagonist, can be used at low doses to decrease WASO (3mg and 6mg: $\mathrm{P}<0.0001$ ), decrease SOL (3mg: $\mathrm{P}=0.0047$; 6mg: $\mathrm{P}=0.0007$ ), and increase TST (3mg and 6mg: $\mathrm{P}<0.0001) .{ }^{10,11}$ At these lower doses, the associated anticholinergic and antiadrenergic blockades of doxepin are less significant, making the side effect profile favorable. ${ }^{10}$ Mirtazapine can be used for older adults with chronic insomnia and comorbid mood disorders with significantly decreased appetite and weight loss. Still, it must be used with caution due to an elevated sedation risk. ${ }^{11}$

\section{BENZODIAZEPINES}

Once considered first-line and now falling out of favor, benzodiazepines such as temazepam and lorazepam are still sometimes used to treat chronic insomnia. Though they are efficacious at increasing TST and decreasing SOL, their use is limited by adverse side effects of cognitive and respiratory depression, along with the risk of dependence and withdrawal. These medications are reserved for intermittent and short-term use in those with insomnia refractory to other therapeutic options. ${ }^{10,11}$

\section{SUVOREXANT}

Suvorexant, a reversible dual orexin receptor antagonist, was approved by the FDA to treat insomnia in 2014. ${ }^{10,11}$ The lateral hypothalamus secretes the neuropeptides orexin-A and orexin- $\mathrm{B}$, which bind their receptors in various locations of the brain to promote arousal and wakefulness. ${ }^{10}$ Suvorexant inhibits this arousal activation producing benefits of increased sleep efficiency (10mg: $\mathrm{P}<0.01$; 20mg, 40mg, 80mg: $\mathrm{P}<0.001)$ and WASO ( $\mathrm{P}<0.001$ for all doses) compared to placebo in RCTs. ${ }^{11,20}$

\section{MELATONIN AGONISTS}

Ramelteon, a melatonin agonist, is a slightly less effective medication used to treat insomnia by reducing SOL 7.06 minutes $(\mathrm{P}<0.001)$, increasing TST 8.25 minutes $(\mathrm{P}=0.013)$ and subjectively improving sleep quality $(\mathrm{P}<0.001)$ compared to placebo. ${ }^{11,21}$ It has a safe side-effect profile but is more expensive than other therapeutic options described. Controlled release melatonin (1-3mg) can be used but lacks FDA approval and regulation, causing potency and drug interaction concerns. ${ }^{11}$

\section{ZOLPIDEM}

Zolpidem is a sedative-hypnotic type medication used for the treatment of insomnia in adults. It comes in both immediate and extended-release forms; the immediate release preparations are used to treat symptoms related to delayed sleep onset. The extended-release preparation treats both delayed sleep onset and decreased sleep latency. For immediate release formulations, women should be started on a dose of $5 \mathrm{mg}$ and men with 5 or $10 \mathrm{mg}$ immediately before bedtime. Women should begin with $6.25 \mathrm{mg}$ and men with $6.25 \mathrm{mg}$ or $12.5 \mathrm{mg}$ if using extended-release formulations. In patients 65 years or older, the minimum dose should be used to minimize adverse effects, not exceeding $5 \mathrm{mg}$ for immediate release and $6.25 \mathrm{mg}$ for extended release. Zolpidem should only be used for short-term treatment of insomnia and should only be taken when the patient has 7 to 8 hours to sleep before being active again. Caution should be used when prescribing this medication to patients taking other drugs, especially medicines for seizures, sleep, anxiety, muscle relaxants, or opioids. ${ }^{22}$ Pregnant women should only be prescribed zolpidem when potential benefits outweigh potential risks to the fetus as there are no adequate and well-controlled studies of use in pregnant women. For elderly or debilitated patients, the risk of impaired motor 
or cognitive performance is higher, and patients should be monitored more closely. All patients, regardless of age, should be monitored for adverse effects once therapy is initiated, specifically for the remission of insomnia symptoms, abnormal thinking or behavioral changes, or severe reactions such as anaphylaxis. Patients should also be educated on possible withdrawal effects and CNS depressant effects resulting from the medication. ${ }^{23}$

\section{MECHANISM OF ACTION}

Zolpidem is a non-benzodiazepine compound that shows a rapid-onset, short-duration hypnotic effect by binding to benzodiazepine receptors, particularly in the cerebellum, indicating a stronger binding preference for $\mathrm{BZ}(\omega)$ receptors. $\mathrm{BZ}(\omega)$ binding sites are associated with the $\mathrm{GABA}_{\mathrm{A}}$ subtype of receptors, a ligand-gated ion channel with five subunits for the inhibitory neurotransmitter GABA. Unlike benzodiazepines, which bind in a non-discriminatory fashion to all BZ subtypes, zolpidem binds best to $\mathrm{BZ}(\omega)$ receptors containing $\alpha_{1}$ subunits, evidenced by low concentrations of zolpidem potentiating the effects of GABA. In contrast, higher concentrations of zolpidem are required to potentiate the effects of GABA in receptors containing $\alpha_{2}$ and $\alpha_{3}$ subunits. There is little to no response in $\alpha_{5}$ containing receptors. ${ }^{24}$ Subunit binding to the $\mathrm{GABA}_{\mathrm{A}}$ receptor contributes to the sedative, anticonvulsant, anxiolytic, and myorelaxant effects of zolpidem. The BZ $(\omega)$ receptor is found primarily on the Lamina IV of the brain sensorimotor cortical regions, the substantia nigra pars reticulata, the cerebellum molecular layer, the olfactory bulb, the ventral thalamic cortex, the pons, the inferior colliculus, and the globus pallidus. ${ }^{25}$ When administered, zolpidem produces slow waves ( 2 to $4 \mathrm{~Hz}$ ) on EEG with only short intervals of fast waves (12 to $14 \mathrm{~Hz}$ ) at high doses. This effect is preferable to benzodiazepines, which produce a greater degree of fast-wave activity that is thought not to correspond to a pattern of normal sleep. The increase in slowwave or non-rapid eye movement sleep caused by zolpidem has been confirmed in vivo by EEG on cats and rats. In these studies, zolpidem increased the non-rapid eye movement sleep with little effect on rapid eye movement sleep except at high doses. ${ }^{24}$

\section{PHARMACODYNAMICS}

Zolpidem is an imidazopyridine used as a sleep-inducing medication to treat chronic insomnia, characterized by difficulties with sleep onset and/or sleep maintenance. ${ }^{26}$ It is important to note that zolpidem is structurally different from benzodiazepines. ${ }^{27}$ Zolpidem enhances the inhibitory neurotransmitter $r$-aminobutyric acid (GABA) activity by selective agonism at the benzodiazepine-1 $\left(\mathrm{BZ}_{1}\right)$ receptor. This results in increased conductivity of chloride, hyperpolarization of neurons, and inhibition of the action potential, which overall decreases neuronal excitability and leads to the sedative and hypnotic effects seen while taking this medication. ${ }^{26,27}$ Since zolpidem is selective for the $\mathrm{BZ}_{1}$ receptor alpha ${ }_{1} /$ alpha $_{5}$ subunits compared to the $\mathrm{BZ}_{2}$ receptor site. It exhibits minimal anxiolytic, myorelaxant, and anticonvulsant side effects associated with agonism at the $\mathrm{BZ}_{2}$ receptor site. ${ }^{26}$ The predominance of $\mathrm{BZ}_{1}$ receptor on structures important for regulating sleep, including Lamina IV of the sensorimotor cortical regions, substantia nigra (pars reticulata), cerebellum molecular layer, olfactory bulb, ventral thalamic complex, pons, inferior colliculus, and globus pallidus, explains why zolpidem is important for the preservation of deep sleep stages 3 and $4 .^{27}$

\section{PHARMACOKINETICS}

Zolpidem exhibits biphasic absorption characteristics showing rapid initial absorption at the gastrointestinal tract and extended plasma concentrations beyond three hours after administration.CYP3A4 enzymes predominantly metabolize 26 zolpidem, and to a lesser extent, by CYP2C9, CYP1A2, CYP2D6, and CYP2C19 enzymes. ${ }^{28}$ Zolpidem is converted to inactive metabolites that are eliminated primarily by renal excretion. ${ }^{26}$ It has been suggested that CYP2C9*1/*3 genotype does not affect the plasma exposure of zolpidem. ${ }^{28}$ The mean elimination half-life of zolpidem is 2.8 hours ranging from 1.62 to 4.05 hours. ${ }^{26}$ Food-effect studies have suggested that administration of zolpidem immediately after a meal is associated with faster sleep onset. $^{26}$ Zolpidem has shown no rebound or withdrawal effects, and individuals on the regimen have experienced good daytime alertness. ${ }^{26,27}$ The major metabolic routes associated with the medication are oxidation and hydroxylation. ${ }^{26}$ Zolpidem is approximately $92 \%$ bound to plasma proteins, with absolute bioavailability of zolpidem being approximately $70 \% .^{26,27}$

It is advised to reduce dosing in patients with renal and hepatic disease and avoid zolpidem altogether in patients with known hypersensitivity to zolpidem or any inactive ingredients in the formulation. ${ }^{27}$ Coadministration of haloperidol, cimetidine, ranitidine, chlorpromazine, warfarin, digoxin has not been shown to alter the pharmacokinetics of zolpidem. ${ }^{27}$ However, caution is advised for patients on Flumazenil, as it antagonizes the hypnotic effects of zolpidem. ${ }^{27}$ Furthermore, it has been observed that volunteers treated with imipramine plus zolpidem developed anterograde amnesia. ${ }^{27}$

The clearance of zolpidem in children is three times higher than in young adults and is lower in the elderly. ${ }^{29}$ Hence the dosing of zolpidem should be lowered for elderly patients. The lowering of the dose of zolpidem proves to be beneficial for elderly individuals because they are more likely to show symptoms of chronic insomnia. Most importantly, they are more likely to suffer from adverse side effects of medications that influence the central nervous system. $^{29}$ Zolpidem is also reported to have a lower risk of causing rebound insomnia when discontinued. ${ }^{29}$ There are no significant differences in the pharmacokinetic parameters between various racial groups and gender. ${ }^{29}$

\section{ADVERSE EFFECTS OF ZOLPIDEM}




\section{FALLS AND FRACTURES}

Zolpidem has been associated with an increased risk of falls in hospitalized patients with an OR of $4.28(\mathrm{P}<0.001)$ when prescribed short-term for insomnia. ${ }^{30,31}$ The relative risk (RR) for hip fractures in patients taking zolpidem was described as 1.92 (95\% CI 1.65-2.24; $\mathrm{P}<0.001$ ), with hip fractures being the most commonly seen. ${ }^{30,32}$ A recent metaanalysis, including two cohort studies $(\mathrm{OR}=2.10 ; 95 \% \mathrm{CI}$ 1.76-2.49) and eight case-controls $(\mathrm{OR}=1.53 ; 95 \% \mathrm{CI}$ 1.31-1.77), demonstrated a significant association between zolpidem and a risk of fractures separately and combined $(\mathrm{OR}=1.63$; 95\% CI 1.42-1.87). The subgroup analysis within the study demonstrated an increased risk of fractures in those taking z-drugs compared to a control group with insomnia $(\mathrm{OR}=1.28 ; 95 \%$ CI $1.08-1.53)$ and even when restricted to age $>65$ years old $(\mathrm{OR}=1.70 ; 95 \%$ CI $1.36-2.12)$. Additionally, there was an association between zolpidem use and risk of non-specific injury $(\mathrm{OR}=2.05 ; 95 \% \mathrm{CI}$ $1.95-2.15) .33,34$

\section{NEUROPSYCHOLOGICAL ADVERSE EFFECTS}

A systematic review and meta-analysis of 20 studies demonstrated that zolpidem has specific adverse effects on cognition rather than a more generalized cognitive depression seen in benzodiazepines. ${ }^{35}$ This review demonstrated significant decreases in attention (Cohen's $d$ of -0.56 ; $95 \%$ CI -0.93 to -0.18 ) and verbal memory (Cohen's $d$ of -0.46 ; 95\% CI -0.66 to -0.25 ), compared to placebo without significant psychomotor disturbances. ${ }^{35}$ This was further corroborated by a double-blind cross-over study where zolpidem improved critical flicker fusion (CFF) testing, a measure of psychomotor function, compared to placebo $(\mathrm{F}=8.51$, $\mathrm{P}=0.03) .36$

However, caution should be used in giving zolpidem during an inpatient setting. A case series of 119 inpatients aged 50 or older demonstrated that a majority (80.8\%) of ADRs were central nervous system (CNS)-related such as confusion, dizziness, and daytime drowsiness. Patients with a baseline functional impairment are at significant risk for these CNS ADRs ( $\mathrm{P}=0.003) .{ }^{37}$

Complex behaviors performed in a "sleep-like" state have been frequently described in association with zolpidem characterized by reduced control of motor functions, reduced awareness of one's surroundings, difficulty thinking, amnesia, and irrational speech. ${ }^{38}$ The Therapeutic Drugs Association (TGA) reported that $10 \%$ of the adverse reactions with zolpidem mentioned "sleep-driving". 39 These cases were reported in both therapeutic and supratherapeutic doses of zolpidem. Legally, the lack of clear understanding of the patient's awareness or volition during this sleep-like state presents a dilemma when someone ingests zolpidem and commits a crime they do not remember. Even more perplexing is the degree of complexity of behavior a person can complete while in this state. This is an essential point in cases of vehicular homicide or homicide. ${ }^{38}$ There have been 5 cases of homicide linked to the use of zolpidem in patients with concurrent mood or anxiety disorders who were taking an antidepressant. ${ }^{30}$ Four of these cases were homicide directed at a spouse or sig- nificant other with extreme and violent overkill in all four cases. The final case of the five was a vehicular homicide. ${ }^{30}$

A retrospective, case-control study demonstrated a significant association of zolpidem to parasomnias (OR 4.34; $\mathrm{P}<0.0001$ ), amnesia (OR 2.78; $\mathrm{P}<0.0001$ ), hallucinations (OR 1.69; $\mathrm{P}<0.0001$ ), and suicidality (OR 1.70; $\mathrm{P}<0.0001)$, which was adjusted for patient demographics and simultaneous medication use. Movement-based parasomnias had the strongest correlation, with an odds ratio (OR) of 34.39 (95\% CI of 31.39-37.68) when adjusted for patient demographics and an OR of 35.20 (CI 31.65-39.14) when adjusting for drug-exposure covariates. Between 2006 and 2009, there was strong public scrutiny of zolpidem and associated significant increases in parasomnias (OR 7.65; $\mathrm{P}<0.05)$, movement-based parasomnias (OR 64.92; $\mathrm{P}<0.05)$, and amnesias (OR 4.29; $\mathrm{P}<0.05$ ). Although there was a significant association with these adverse drug reactions before the media storm, this highlights the importance of considering notoriety bias secondary to media coverage. ${ }^{40}$

A systematic review of 24 previous studies of sleepwalking associated with zolpidem demonstrated that the association was not dependent on age, dose, medical history, or even a history of sleepwalking at any time before zolpidem use. ${ }^{41}$ It is important to counsel patients on this, as the product information is given with the medication only mentions sleepwalking as a risk if combined with another CNS depressant or at doses greater than $10 \mathrm{mg}$. In this review, zolpidem was found to have the strongest association with sleepwalking throughout the literature out of all prescribed medications included in the study. ${ }^{41}$

Suicide attempts and completion have been successfully linked with zolpidem use (OR 2.08; 95\% CI 1.83-2.63) in patients regardless of the presence of comorbid psychiatric illness. ${ }^{30,42}$ A review by the International Journal of Neuropsychopharmacology demonstrated that out of 23,420 dependence and withdrawal type of ADRs, 102 cases showed intentional "self-injurious behavior" $(0.5 \%), 44$ cases included "suicidal behavior" (0.2\%), and 3,101 cases were described as "suicidal attempts" (13.2\%). ${ }^{43}$ Compared to zopiclone and zaleplon, zolpidem had the highest rates of fatal outcome (20.3\%) with these types of ADRs. ${ }^{43}$

\section{ABUSE, DEPENDENCE, \& WITHDRAWAL}

A significant attraction to the use of $\mathrm{z}$-drugs was the expectation for lower rates of dependence, abuse, and withdrawal than benzodiazepines. Still, studies have demonstrated that this may not be the case. Rebound insomnia and withdrawal symptoms have been linked to zolpidem use after stopping the medication suddenly, even if the patient took the therapeutic dose, with an even higher risk in those with concurrent drug or alcohol dependence. ${ }^{43,44}$ Misuse-, abuse-, dependence-, and withdrawal-related ADRs have been shown to make up $11.35 \%$ (95\% CI 11.21-11.49\%) of total ADRs seen with zolpidem.

Data on dependence and abuse with zolpidem was obtained from the Center for Evaluation and Information on Pharmacodependence (CEIP) during the post-marketing period of 2003-2010 in France and demonstrated a consistently increasing rate of "Suspect Prescriptions Possibly Indicating Abuse" during this time. Zolpidem was the drug 
most associated with these types of falsified prescriptions in 2009. This paper compared 30 cases of dependence and abuse in zolpidem users, finding an average age of 38 years old and range of daily dosage being 50-2000mg (average of $616.61 \mathrm{mg}$ ). Concurrent disorders of substance abuse (40.0\%) and psychiatric conditions (13.3\%) collectively made up over half of the cases. ${ }^{45}$

A double-blind, placebo-controlled study was performed on 11 healthy participants without a personal or family substance abuse history to investigate subjective effects of zolpidem. After receiving one of the four treatments $(0,5$, 10 , or $20 \mathrm{mg}$ zolpidem), the patients began by answering the Addiction Research Center Inventory (ARCI). Within the ARCI, zolpidem was noted to affect two parameters of drug effects: intoxicating-like feelings (Pentobarbital-Chlorpromazine-Alcohol group; PCAG) and stimulating-like effects (Benzedrine group; BG). PCAG $\left(F_{(3,30)}=6.68, p<0.001\right)$ and $\mathrm{BG}\left(F_{(3,30)}=4.77, p<0.01\right)$ associated with zolpidem were both significant. A visual analog scale (VAS) was used to report how they were feeling at that moment, with the most reported being "sleepy" $\left(F_{(3,330)}=12.93, p<0.001\right)$, "high" $\left(F_{(3,330)}=9.95, p<0.001\right)$, and "good effects" $\left(F_{(3,330)} 13.53, p<0.001\right)$ at the highest doses. Interestingly, a choice of drug versus money ranging from $\$ 0.35$ to $\$ 10.00$ always resulted in money over zolpidem. ${ }^{46}$

There have been multiple cases reported of seizures following the withdrawal of zolpidem. ${ }^{44,47}$ Most cases have demonstrated that withdrawal seizures occurred in patients taking daily dosages of around $450-600 \mathrm{mg} / \mathrm{day}$, but some reported them as low as $160 \mathrm{mg} / \mathrm{day}$. All instances of withdrawal seizures from zolpidem have been successfully treated with diazepam, a long-acting benzodiazepine, which allows a prolonged taper of neuronal inhibition. ${ }^{47}$

Rebound insomnia has been a concern to prescribers of zolpidem. Studies have demonstrated that the first night after discontinuation of zolpidem, there was a nonsignificant difference in total sleep time ( -2.4 minutes; $95 \%$ CI -11.4 to 6.6). However, sleep onset latency has been demonstrated to be significantly increased on the first night after stopping zolpidem (13.0 minutes; 95\% CI 4.3-21.7; $\mathrm{P}<0.01$ ). After $2-4$ weeks post-discontinuation, there were no signs of rebound insomnia, and this was sustained for over 6 months. ${ }^{48}$

\section{GENDER-RELATED DISCREPANCIES}

The Food and Drug Administration (FDA) released a somewhat unsubstantiated statement in the New England Journal of Medicine (2013) that an increased risk of sedation and driving impairment in women compared to men with the most significant risk seen above $50 \mathrm{ng} / \mathrm{mL} .{ }^{49}$ This was accompanied by a recommendation for women to receive lower doses (5mg of immediate-release [IR], $6.25 \mathrm{mg}$ of extended-release [ER]). ${ }^{49,50}$ While previous studies have already demonstrated a lower clearance in women than men, the FDA recommendation on dosing was based solely on gender differences rather than weight-normalized dosing. ${ }^{50-52}$

A commentary article was published in 2019 by the Journal of Clinical Psychopharmacology using data from a double-blind, single-dose, random sequence, 3-way cross-over study of $10 \mathrm{mg}$ zolpidem immediate-release (IR), $12.5 \mathrm{mg}$ zolpidem extended-release (ER), and placebo. ${ }^{50}$ The gender differences in drug concentrations at the critical point described in the original FDA release ( 8 hours after 10mg IR or $12.5 \mathrm{mg}$ ER) were measured. It was again demonstrated that female subjects had a lower zolpidem clearance than males $(3.73 \mathrm{~mL} / \mathrm{min} / \mathrm{kg}$ vs. $4.02 \mathrm{~mL} / \mathrm{min} / \mathrm{kg}$ ) even after adjustment for body weight, but this was not significant $(P=0.085)$. Women had a non-significantly higher mean plasma concentration than men after 8 hours for the 10mg IR (28 vs. $20 \mathrm{ng} / \mathrm{mL}$ ) and the $12.5 \mathrm{mg}$ MR (33 vs. $28 \mathrm{ng} / \mathrm{mL}$ ). Women did tend to have more frequent dose concentrations reaching or exceeding the $50 \mathrm{ng} / \mathrm{mL}$ limit set by the FDA "correlating" high risk for sedation $(12.5 \%$ vs. $0 \%$ in $10 \mathrm{mg}$ IR; $18.8 \%$ vs. $8 \%$ in $12.5 \mathrm{mg}$ ER). ${ }^{49}$ Importantly, there were no difference in the Digital-Symbol Substitution Test (DSST) scores indicative of psychomotor performance, electroencephalographic (EEG) beta amplitude indicative of drug effects, or observer-rated sedation between genders, regardless of drug concentration levels above $50 \mathrm{ng} / \mathrm{mL}$ in some subjects. ${ }^{50}$

This study highlights the illegitimacy of the FDA recommendations in 2013 to give women dosage reductions in zolpidem to avoid sedation and driving impairment. Furthermore, the drug concentration "cut-off" of $50 \mathrm{ng} / \mathrm{mL}$ for adverse events was not proven. It is essential to pay attention to the fact that underdosing this population could be even more hazardous, as sleep deprivation is associated with impaired reaction time and judgement. ${ }^{50}$

\section{PREGNANCY OUTCOMES}

The FDA has classified zolpidem as a category $\mathrm{C}$ drug based on adverse outcomes seen in animal fetal development. A nationwide, population-based study compared the incidence of adverse pregnancy outcomes in mothers who had taken zolpidem during pregnancy compared to those who did not. The control group was adjusted for the infant's gender, parity, maternal educational level, gestational hypertension, gestational diabetes, pre-eclampsia/eclampsia, and anemia. In the mothers exposed to zolpidem, there was an increased incidence of low birth weight $(\mathrm{OR}=1.39$; $\mathrm{P}<0.001$ ), preterm delivery (OR 1.49; $\mathrm{P}<0.001$ ), small for gestational age $(\mathrm{SGA})$ babies $(\mathrm{OR}=1.34 ; \mathrm{P}<0.001)$, and cesarean deliveries $(\mathrm{OR}=1.74 ; \mathrm{P}<0.001)$. The rate of congenital abnormalities was not significantly increased with zolpi$\operatorname{dem}(0.48$ vs $0.65 \% ; \mathrm{P}=0.329) .{ }^{53}$

\section{OBSTRUCTIVE SLEEP APNEA}

A double-blind, placebo-controlled, cross-over study was performed to assess the role of hypnotics in obstructive sleep apnea (OSA) mechanisms, such as upper airway function and breathing during sleep. Participants were randomized to either temazepam $10 \mathrm{mg}$, zolpidem $10 \mathrm{mg}$, zopiclone $7.5 \mathrm{mg}$, or placebo, then electroencephalograms (EEGs), electrooculogram (EOGs), and submentalis electromyograms (EMGs) were used for measurements. A pressuretipped catheter was used to determine epiglottic pressure at the base of the tongue, and intramuscular electrodes measured genioglossus EMG. Minute ventilation, inspiratory and expiratory time, peak inspiratory flow, and upper airway resistance parameters in those on temazepam, zolpi- 
dem, or zopiclone were all non-significantly different from placebo $(\mathrm{P}>0.05)$. The frequency of breaths per minute was increased in all three drug groups compared to placebo $(\mathrm{P}<0.03)$. Both zolpidem (27\%; $\mathrm{P}=.02)$ and zopiclone $(37 \%$; $\mathrm{P}<0.001)$ significantly increased respiratory arousal threshold compared to the placebo group, while temazepam did not $(\mathrm{P}=0.17)$. None of the three drugs negatively impacted passive upper airway collapsibility compared to placebo. Interestingly, zolpidem paradoxically increased genioglossus muscle responsiveness to airway closure compared to placebo $(\mathrm{P}=0.03)$, unlike zopiclone $(\mathrm{P}=0.98)$ and temazepam $(\mathrm{P}=0.54) .{ }^{54}$ This is a critical point, as hypnotics are usually contraindicated in OSA. The theory that neuronal inhibition at the hypoglossal from GABA activation should cause a decreased reflex sensitivity. ${ }^{54}$ Table 1 summarizes the results discussed in this section.

\section{CONCLUSION}

Insomnia is a diagnosis that can be frustrating to live with, and patients need physician support in dealing with and treating their condition. Insomnia is linked to fatigue, distractibility, mood instability, decreased satisfaction, and overall decreased quality of life. Optimal therapy can aid patients in returning to baseline and increase their quality of life. There are various lifestyle modifications, and medications available to treat insomnia-among these are patient education about avoiding caffeine intake and daytime napping, cognitive behavioral therapy, hypnosis, sleep restriction, melatonin agonists, benzodiazepines, antidepressants, orexin receptor antagonists, and non-benzodiazepine hypnotics. Zolpidem is a helpful drug for the treatment of insomnia in conjunction with cognitive-behavioral therapy. Like all drugs, it does have some side effects, and they are usually tolerable to patients for the payoff in increased quality of life. When prescribed to elderly patients, the dose should be adjusted to account for their slower drug metabolism. Still, zolpidem is considered a reasonable choice of therapy because it has a lower incidence of residual daytime sleepiness and risk of falls when compared to other drugs. All patients should be warned about adverse effects that can present with use, including falls and subsequent fractures, increased risk of suicide attempts regardless of comorbid psychiatric diagnoses, complex behaviors performed in a sleep-like state, dependence and rebound insomnia, obstructive sleep apnea, and decreases in attention and verbal memory, and next-day impairment. The most concerning adverse effects, which are often the most publicized, include the complex behaviors that have been seen in patients taking zolpidem, such as sleeping, hallucinations, increased suicidality, driving cars while asleep, and even a few cases of committing homicide. Prescribers should carefully weigh the potential benefits and harms that can arise from patients taking zolpidem and make decisions for whether or not to prescribe it as well as the dosage on a case-by-case basis, taking into account both the psychical and psychiatric risks posed to the patient that has insomnia versus if the patient were to take zolpidem to treat their condition.
Submitted: June 01, 2021 EST, Accepted: June 16, 2021 EST 
Table 1. Scientific Evidence on ADRs of Zolpidem

\begin{tabular}{|c|c|c|c|}
\hline $\begin{array}{l}\text { Author } \\
\text { (Year) }\end{array}$ & Groups Studied and Methods & $\underline{\text { Results and Findings }}$ & Conclusions \\
\hline $\begin{array}{l}\text { Stranks E. et } \\
\text { al. (2014) }\end{array}$ & $\begin{array}{l}\text { Meta-analysis of } 20 \text { RCTs or } \\
\text { randomized cross-over trials } \\
\text { from } 1980-2013 \text { assessing } \\
\text { cognitive effects of zolpidem on } \\
\text { computerized databases } \\
\text { (Medline and PsycINFO). } \\
\text { Primary measures were Cohen's } \\
d \text { effect sizes ( } 0.2 \text { small, } 0.4 \\
\text { medium, and }>0.6 \text { large) in each } \\
\text { cognitive domain. }\end{array}$ & $\begin{array}{l}\text { Cohen's } d \text { of }-0.56 \text { for attention } \\
(95 \% \mathrm{Cl}-0.93 \text { to }-0.18),-0.46 \text { for } \\
\text { verbal memory }(\mathrm{Cl}-0.66 \text { to } \\
-0.25),-0.15 \text { for speed of } \\
\text { processing }(\mathrm{Cl}-0.31 \text { to } 0.02) \text {, and } \\
-0.01 \text { for working memory }(\mathrm{Cl} \\
-0.17 \text { to } 0.16) \text {. }\end{array}$ & $\begin{array}{l}\text { Zolpidem was associated with } \\
\text { moderate cognitive decline in } \\
\text { specific domains of attention and } \\
\text { verbal memory; nonsignificant } \\
\text { decrease in processing and } \\
\text { working memory speed. }\end{array}$ \\
\hline $\begin{array}{l}\text { Wong C. et al. } \\
(2020)\end{array}$ & $\begin{array}{l}\text { Analysis of patient data }(2,131, \\
368 \text { reports) in FAERS database } \\
\text { from 2003-2012 for association } \\
\text { of zolpidem exposure with } \\
\text { adverse events. Year-by-year } \\
\text { unadjusted odds ratios were } \\
\text { used as the primary measure } \\
\text { then adjusted for patient } \\
\text { demographics and cofounding } \\
\text { drug exposures. }\end{array}$ & $\begin{array}{l}\text { OR for zolpidem exposure with } \\
\mathrm{P}<0.0001 \text { for the following: } \\
\text { parasomnias (OR 4.34), } \\
\text { movement parasomnias (OR } \\
\text { 35.20), amnesia (OR 2.78), } \\
\text { hallucinations (OR 1.69), and } \\
\text { suicidality (OR 1.70). }\end{array}$ & $\begin{array}{l}\text { Zolpidem exposure was } \\
\text { associated with a significant } \\
\text { increase in ADRs of parasomnias, } \\
\text { amnesia, hallucinations, and } \\
\text { suicidality compared to placebo. }\end{array}$ \\
\hline $\begin{array}{l}\text { Greenblatt D. } \\
\text { et al. (2019) }\end{array}$ & $\begin{array}{l}\text { Double-blind, single-dose, } \\
\text { random sequence, 3-way cross- } \\
\text { over study analyzing male and } \\
\text { female data from a previous } \\
\text { clinical pharmacokinetic- } \\
\text { pharmacodynamic study of } \\
\text { zolpidem IR } 10 \mathrm{mg} \text {, zolpidem XR } \\
12.5 \mathrm{mg} \text {, and placebo; combined } \\
\text { these results with literature } \\
\text { review on adverse effects of } \\
\text { zolpidem. }\end{array}$ & $\begin{array}{l}\text { Female subjects had lower } \\
\text { clearance of zolpidem than males } \\
(3.73 \mathrm{~mL} / \mathrm{min} / \mathrm{kg} \text { vs. } 4.02 \mathrm{~mL} / \mathrm{min} / \\
\mathrm{kg} ; \mathrm{P}=0.085) \text {. Women had } \\
\text { higher mean plasma } \\
\text { concentration than men after } 8 \\
\text { hours for the } 10 \mathrm{mg} \mathrm{IR}(28 \mathrm{vs.} 20 \\
\mathrm{ng} / \mathrm{mL} \text { ) and the } 12.5 \mathrm{mg} \mathrm{MR}(33 \\
\mathrm{vs..} 28 \mathrm{ng} / \mathrm{mL}) \text {. No significant } \\
\text { difference in DSST scores, EEG } \\
\text { beta amplitude, or subjective } \\
\text { sedation scores between } \\
\text { genders. No correlation of } 50 \mathrm{ng} / \\
\text { mL concentration being the } \\
\text { boundary for impairment. }\end{array}$ & $\begin{array}{l}\text { The FDA recommendation to } \\
\text { reduce the dosage of zolpidem in } \\
\text { women is unfounded and } \\
\text { unsupported by scientific } \\
\text { evidence. Highlights that } \\
\text { underdosing here could be just } \\
\text { as dangerous as sleep } \\
\text { deprivation can lead to } \\
\text { functional and cognitive } \\
\text { impairment as well. }\end{array}$ \\
\hline $\begin{array}{l}\text { Westermeyer } \\
\text { J. et al. (2020) }\end{array}$ & $\begin{array}{l}\text { Post-2000 literature review of } \\
\text { adverse events described with } \\
\text { zolpidem use; the primary } \\
\text { measure was odds ratio. Also, } \\
\text { described legal impacts of some } \\
\text { zolpidem cases through case } \\
\text { reports. }\end{array}$ & $\begin{array}{l}\text { Increased risk of inpatient falls } \\
\text { (OR 4.28; } P<0.001 \text { ) and fractures } \\
\text { (OR 1.92; } P<0.001 \text { ) with hip } \\
\text { fracture being the predominant } \\
\text { type. Increased suicide attempts } \\
\text { and completions (OR } 2.0895 \% \mathrm{Cl} \\
1.65-2.24 ; \mathrm{P}<0.001) \text { regardless } \\
\text { of comorbid mood disorders } \\
\text { being present. }\end{array}$ & $\begin{array}{l}\text { Zolpidem has been successfully } \\
\text { linked to increased falls, } \\
\text { fractures (hip), suicide attempts/ } \\
\text { completions. In addition, there } \\
\text { have been five homicidal cases } \\
\text { associated ( } 1 \text { vehicular; } 4 \text { direct } \\
\text { and violent). }\end{array}$ \\
\hline $\begin{array}{l}\text { Stallman H. } \\
\text { et al. (2018) }\end{array}$ & $\begin{array}{l}\text { A systematic review of } \\
\text { medications associated with } \\
\text { sleepwalking behavior using } \\
\text { CINAHL, EMBASE, PsychINFO, } \\
\text { PubMed, and ScienceDirect } \\
\text { databases from the original date } \\
\text { of each database to March } 2016 \\
\text { was performed. }\end{array}$ & $\begin{array}{l}\text { Twenty-four total studies } \\
\text { demonstrated the link between } \\
\text { zolpidem and sleepwalking; no } \\
\text { association with age, dosage, } \\
\text { history of sleepwalking, or } \\
\text { medical history. }\end{array}$ & $\begin{array}{l}\text { Sleepwalking has been } \\
\text { associated with zolpidem more } \\
\text { frequently than any other } \\
\text { medication in this literature } \\
\text { review and is not limited to } \\
\text { doses exceeding 10mg or } \\
\text { concurrent CNS depressant use. }\end{array}$ \\
\hline $\begin{array}{l}\text { Andrade C. et } \\
\text { al. (2018) }\end{array}$ & $\begin{array}{l}\text { Review of recent meta-analyses } \\
\text { on the risk of fractures falls, and } \\
\text { other injuries in those taking } \\
\text { zolpidem. Odds ratios were used } \\
\text { to measure the association of } \\
\text { zolpidem exposure to these } \\
\text { variables. }\end{array}$ & $\begin{array}{l}\text { Association of zolpidem and } \\
\text { fractures: } 2 \text { cohort studies (OR = } \\
2.10 ; 95 \% \mathrm{Cl} 1.76-2.49), 8 \text { case- } \\
\text { controls }(\mathrm{OR}=1.53 ; 95 \% \mathrm{Cl} \\
1.31-1.77), \text { combined (OR }=1.63 \text {; } \\
95 \% \mathrm{Cl} 1.42-1.87) \text {. Subgroup } \\
\text { analysis of } z \text {-drugs and fractures } \\
\text { demonstrated OR }=1.28(95 \% \mathrm{Cl} \\
1.08-1.53) \text { compared to the } \\
\text { control group with insomnia and } \\
\text { increased fracture risk when } \\
\text { restricted to age }>65 \mathrm{y} \text { was } \mathrm{OR}= \\
1.70(95 \% \mathrm{Cl} 1.36-2.12) \text {. }\end{array}$ & $\begin{array}{l}\text { Zolpidem increases the risk of } \\
\text { fractures in all ages and in those } \\
>65 \text { yo and the risk of non- } \\
\text { specific injury compared to } \\
\text { controls with insomnia. }\end{array}$ \\
\hline
\end{tabular}




\begin{tabular}{|c|c|c|c|}
\hline & & $\begin{array}{l}\text { Increased risk of non-specific } \\
\text { injury in those taking zolpidem } \\
\text { with } \mathrm{OR}=2.05(95 \% \mathrm{Cl} \\
1.95-2.15) .\end{array}$ & \\
\hline $\begin{array}{l}\text { Schifano F. et } \\
\text { al. (2019) }\end{array}$ & $\begin{array}{l}\text { Analyzed datasets describing } \\
\text { adverse drug reactions (misuse, } \\
\text { abuse, dependence, withdrawal) } \\
\text { with z-drugs provided by } \\
\text { European Medicines Agency } \\
\text { (EudraVigilance System). }\end{array}$ & $\begin{array}{l}\text { Misuse, abuse, dependence, } \\
\text { withdrawal complaints made up } \\
11.35 \% \text { ( } 95 \% \mathrm{Cl} 11.21-11.49 \%) \\
\text { of total ADRs associated with } \\
\text { zolpidem. There were higher } \\
\text { rates of fatal outcomes with } \\
\text { these types of ADRs in zolpidem } \\
(20.3 \%) \text { compared to zopiclone } \\
\text { (9.33\%) and zaleplon (1.1\%). }\end{array}$ & $\begin{array}{l}\text { Zolpidem ADRs are significantly } \\
\text { made up of specific misuse, } \\
\text { abuse, withdrawal, and } \\
\text { dependence complaints; the } \\
\text { outcomes of these } \\
\text { manifestations are more } \\
\text { frequently fatal than other z- } \\
\text { drugs. }\end{array}$ \\
\hline $\begin{array}{l}\text { Vigneau C. et } \\
\text { al. (2014) }\end{array}$ & $\begin{array}{l}\text { Post-marketing period } \\
(2003-2010) \text { data collected by } \\
\text { national CEIP network } \\
\text { demonstrating records of } \\
\text { dependence or abuse and } \\
\text { literature analysis. Thirty case } \\
\text { reports data and characteristics } \\
\text { were analyzed. }\end{array}$ & $\begin{array}{l}\text { There were consistent yearly } \\
\text { increases in the number of } \\
\text { suspicious prescriptions for } \\
\text { zolpidem suspected to be } \\
\text { falsified during the time period. } \\
\text { In addition, case report analysis } \\
\text { demonstrated average age of } 38 \\
\text { years old in abusers, average } \\
\text { daily dose of } 616.1 \mathrm{mg} / \mathrm{d} \text {, } \\
\text { comorbid psychiatric disorders } \\
\text { in } 13.3 \% \text {, and comorbid } \\
\text { substance abuse in } 40 \% \text {. }\end{array}$ & $\begin{array}{l}\text { Zolpidem was the number one } \\
\text { drug falsified in prescriptions } \\
\text { during the study period. In } \\
\text { addition, abusers take an } \\
\text { extremely high average daily } \\
\text { dose of } 616.1 \mathrm{mg} \text {, suggesting } \\
\text { significant dependence with } \\
\text { chronic users. }\end{array}$ \\
\hline $\begin{array}{l}\text { Licata S. et al. } \\
\text { (2011) }\end{array}$ & $\begin{array}{l}\text { Double-blind, placebo- } \\
\text { controlled study on } 11 \text { healthy } \\
\text { volunteers without personal or } \\
\text { family history of substance } \\
\text { abuse; participants were given } \\
\text { either } 0,5,10 \text {, or } 20 \text { mg zolpidem } \\
\text { then given subjective } \\
\text { assessments (ARCI, VAS, Drug v } \\
\text { Money). Two-way repeated } \\
\text { ANOVAs, one-way ANOVA, and } \\
\text { t-tests were used to measure. }\end{array}$ & $\begin{array}{l}\text { In the ARCI, PCAG } \\
\left(F_{(3,30)}=6.68, p<0.001\right) \text { and } \\
\mathrm{BG}\left(F_{(3,30)}=4.77, p<0.01\right) \\
\text { were both found to be } \\
\text { associated with zolpidem use. } \\
\text { On VAS, "sleepy" } \\
\left(F_{(3,330)}=12.93, p<0.001\right) \text {, } \\
\text { "high" } \\
\left(F_{(3,330)}=9.95, p<0.001\right) \text {, and } \\
\text { "good effects" } \\
\left(F_{(3,330)} 13.53, p<0.001\right) \text { were } \\
\text { most reported at the highest } \\
\text { doses. Drug v. Money always } \\
\text { resulted in the choice of money } \\
\text { relative to placebo regardless of } \\
\text { monetary value. }\end{array}$ & $\begin{array}{l}\text { Zolpidem most commonly causes } \\
\text { subjective feelings of } \\
\text { intoxication or stimulant-like } \\
\text { effects. Feelings of being high } \\
\text { and abuse-related effects were } \\
\text { seen more at higher doses, even } \\
\text { in drug-naïve patients. Despite } \\
\text { these effects, it had no impact on } \\
\text { the hypothetical choice of money } \\
\text { vs. zolpidem (patients would } \\
\text { rather receive } \$ 0.35 \text { over } \\
\text { another zolpidem dose). }\end{array}$ \\
\hline $\begin{array}{l}\text { Wang L. et al. } \\
\text { (2010) }\end{array}$ & $\begin{array}{l}\text { Nationwide, a population-based } \\
\text { study looking at the incidence of } \\
\text { adverse outcomes of pregnancy } \\
\text { in mothers taking zolpidem } \\
\text { during pregnancy compared to } \\
\text { those who did not. }\end{array}$ & $\begin{array}{l}\text { Zolpidem use in mothers had an } \\
\text { increased incidence of low birth } \\
\text { weight }(\mathrm{OR}=1.39 ; \mathrm{P}<0.001) \text {, } \\
\text { preterm delivery }(\mathrm{OR} 1.49 ; \\
\mathrm{P}<0.001), \mathrm{SGA} \text { babies (OR }= \\
1.34 ; \mathrm{P}<0.001) \text {, and cesarean } \\
\text { deliveries (OR }=1.74 ; \mathrm{P}<0.001 \text { ) } \\
\text { compared to mothers who did } \\
\text { not use zolpidem. The rate of } \\
\text { congenital abnormalities was not } \\
\text { significantly increased with } \\
\text { zolpidem ( } 0.48 \text { vs } 0.65 \% ; \mathrm{P}= \\
0.329) \text {. }\end{array}$ & $\begin{array}{l}\text { Zolpidem use in pregnancy is not } \\
\text { associated with an increased risk } \\
\text { of congenital abnormalities (not } \\
\text { a teratogen). However, there are } \\
\text { increased risks associated with } \\
\text { zolpidem use, such as SGA } \\
\text { babies, preterm delivery, LBW } \\
\text { babies, and C-sections. }\end{array}$ \\
\hline $\begin{array}{l}\text { Carberry C. } \\
\text { et al. (2017) }\end{array}$ & $\begin{array}{l}\text { Double-blind, placebo- } \\
\text { controlled, cross-over study; } \\
\text { Participants were randomized to } \\
\text { either temazepam } 10 \mathrm{mg}, \\
\text { zolpidem } 10 \mathrm{mg}, \text { zopiclone } 7.5 \mathrm{mg}, \\
\text { or placebo, then EEGs, EOGs, } \\
\text { EMGs were used for sleep stage } \\
\text { determination. In addition, a } \\
\text { pressure-tipped catheter was } \\
\text { used for epiglottic pressure at } \\
\text { the base of the tongue, and } \\
\text { intramuscular electrodes } \\
\text { measured genioglossus EMG. }\end{array}$ & $\begin{array}{l}\text { Minute ventilation, inspiratory } \\
\text { and expiratory time, peak } \\
\text { inspiratory flow, and upper } \\
\text { airway resistance parameters in } \\
\text { all three groups were } \\
\text { nonsignificant from placebo } \\
\text { ( } P>0.05) \text {. The frequency of } \\
\text { breaths/min was increased in all } \\
\text { three drug groups compared to } \\
\text { placebo }(P<0.03) \text {. Both zolpidem } \\
(27 \% ; P=.02) \text { and zopiclone } \\
(37 \% ; P<0.001) \text { significantly } \\
\text { increased respiratory arousal } \\
\text { threshold compared to the } \\
\text { placebo group. Temazepam did } \\
\text { not }(P=0.17) \text {. No impact on }\end{array}$ & $\begin{array}{l}\text { Zolpidem causes a paradoxical } \\
\text { increase in airway } \\
\text { responsiveness to passive upper } \\
\text { airway collapsibility, calling into } \\
\text { question the common theory of } \\
\text { hypnotics worsening OSA. In } \\
\text { addition, Z-drugs increased } \\
\text { respiratory arousal when } \\
\text { compared to placebo and } \\
\text { benzodiazepines. }\end{array}$ \\
\hline
\end{tabular}




\begin{tabular}{|c|c|c|c|}
\hline & & $\begin{array}{l}\text { passive upper airway } \\
\text { collapsibility compared to } \\
\text { placebo in any group. Zolpidem } \\
\text { increased genioglossus muscle } \\
\text { responsiveness compared to } \\
\text { placebo }(P=0.03) \text { unlike } \\
\text { zopiclone }(P=0.98) \text { and } \\
\text { temazepam }(P=0.54) \text {. }\end{array}$ & \\
\hline $\begin{array}{l}\text { MacFarlane } \\
\text { J. et al. (2014) }\end{array}$ & $\begin{array}{l}\text { Review of the efficacy of } \\
\text { zolpidem in the treatment of } \\
\text { insomnia and safety of zolpidem } \\
\text { by searching PubMed and } \\
\text { Google Scholar. }\end{array}$ & $\begin{array}{l}\text { The first-night post- } \\
\text { discontinuation of zolpidem, } \\
\text { there was a nonsignificant } \\
\text { difference in total sleep time } \\
(-2.4 \text { min; } 95 \% \mathrm{Cl}-11.4 \text { to } 6.6) \text {. In } \\
\text { addition, } \mathrm{SOL} \text { was increased on } \\
\text { the first night after stopping } \\
\text { zolpidem ( } 13.0 \text { minutes; } 95 \% \mathrm{Cl} \\
4.3-21.7 ; \mathrm{P}<0.01) \text {. After } 2-4 \\
\text { weeks post-discontinuation, } \\
\text { there were no signs of rebound } \\
\text { insomnia. }\end{array}$ & $\begin{array}{l}\text { It does not appear that rebound } \\
\text { insomnia is sustained in patients } \\
\text { after discontinuation of } \\
\text { zolpidem, though it may be } \\
\text { present acutely. }\end{array}$ \\
\hline $\begin{array}{l}\text { Ito S. et al. } \\
\text { (2007) }\end{array}$ & $\begin{array}{l}\text { Double-blind cross-over study } \\
\text { comparing psychomotor effects } \\
\text { of } 10 \text { mg zolpidem to placebo by } \\
\text { measuring combined test for } \\
\text { finger dexterity (CTFD), CFF, } \\
\text { simple discriminatory reaction } \\
\text { tests (SDRs), and fifty-meter } \\
\text { sprint. }\end{array}$ & $\begin{array}{l}\text { An only significant difference } \\
\text { between groups was seen in CFF } \\
\text { where the zolpidem group had } \\
\text { better results than placebo } \\
F=8.5(P=0.03) \text {. }\end{array}$ & $\begin{array}{l}\text { Zolpidem can be used in healthy } \\
\text { adults or athletes to improve } \\
\text { sleep without significant } \\
\text { psychomotor function or } \\
\text { physical performance deficits. }\end{array}$ \\
\hline $\begin{array}{l}\text { Mahoney J. } \\
\text { et al. (2004) }\end{array}$ & $\begin{array}{l}\text { Case series of 50-year-old } \\
\text { inpatients }(n=119 \text { ) from } \\
\text { 1993-1997 who received } \\
\text { zolpidem during hospitalization } \\
\text { assessing for ADRs related to } \\
\text { zolpidem use. }\end{array}$ & $\begin{array}{l}21 \text { out of } 26 \text { ADRs were CNS- } \\
\text { related ( } 80.8 \% \text { ) and occurring in } \\
\text { doses of } 5 \mathrm{mg} \text { or } 10 \mathrm{mg} \text {; Patients } \\
\text { having a baseline functional } \\
\text { impairment were at significant } \\
\text { risk of CNS ADRs ( } P=0.003) \text {. }\end{array}$ & $\begin{array}{l}\text { Inpatient use of zolpidem is } \\
\text { associated with a high risk of } \\
\text { CNS ADRs and should be used } \\
\text { with caution in those with } \\
\text { underlying functional } \\
\text { impairment. }\end{array}$ \\
\hline
\end{tabular}




\section{REFERENCES}

1. Burman D. Sleep Disorders: Insomnia. FP Essent. 2017;460:22-28.

2. Schutte-Rodin SL, Broch L, Buysee D, Dorsey C, Sateia M. Clinical guideline for the evaluation and management of chronic insomnia in adults. Journal of Clinical Sleep Medicine. 2008;4(5):487-504. doi:10.566 4/jcsm.27286

3. Patel D, Steinberg J, Patel P. Insomnia in the elderly: A review. Journal of Clinical Sleep Medicine. 2018;14(6):1017-1024. doi:10.5664/jcsm.7172

4. Riemann D, Nissen C, Palagini L, Otte A, Perlis ML, Spiegelhalder K. The neurobiology, investigation, and treatment of chronic insomnia. The Lancet Neurology. Published online 2015. doi:10.1016/S1474-4422(15)00 $\underline{021-6}$

5. Morin CM, Drake CL, Harvey AG, et al. Article number: 15026 NATURE REVIEWS | DISEASE PRIMERS VOLUME. Nature Publishing Group. Published online 2015. doi:10.1038/nrdp.2015.26

6. Kaur H, Bollu PC. Insomnia, Chronic.; 2018.

7. Ohayon MM. Epidemiology of insomnia: What we know and what we still need to learn. Sleep Medicine Reviews. Published online 2002. doi:10.1053/smrv.200 $\underline{2.0186}$

8. Cunnington D, Junge MF, Fernando AT. Insomnia: Prevalence, consequences and effective treatment. Medical Journal of Australia. Published online 2013. do $\mathrm{i}: 10.5694 / \mathrm{mja} 13.10718$

9. Maness DL, Khan M. Nonpharmacologic management of chronic insomnia. American Family Physician. 2016;92(12):1058-1064.

10. Kay-Stacey M, Attarian H. Advances in the management of chronic insomnia. BMJ (Online). 2016;354. doi:10.1136/bmj.i2123

11. Bragg S, Benich JJ, Christian N, Visserman J, Freedy J. Updates in insomnia diagnosis and treatment. The International Journal of Psychiatry in Medicine. 2019;54(5):275-289. doi:10.1177/009121741 $\underline{9860716}$

12. Trauer JM, Qian MY, Doyle JS, Shantha, Rajaratnam MW, Cunnington D. Cognitive behavioral therapy for chronic insomnia: A systematic review and meta-analysis. Annals of Internal Medicine. 2015;163:191-204. doi:10.7326/M14-2841
13. Sivertsen B, Omvik S, Pallesen S, et al. Cognitive behavioral therapy vs zopiclone for treatment of chronic primary insomnia in older adults: A randomized controlled trial. Journal of the American Medical Association. 2006;295(24):2851-2858. doi:1 $\underline{0.1001 / \text { jama.295.24.2851 }}$

14. Wu R, Bao J, Zhang C, Deng J, Long C. Comparison of sleep condition and sleep-related psychological activity after cognitive-behavior and pharmacological therapy for chronic insomnia. Psychotherapy and Psychosomatics. 2006;75(4):220-228. doi:10.1159/000 092892

15. Jacobs GD, Pace-Schott EF, Stickgold R, Otto MW. Cognitive behavior therapy and pharmacotherapy for insomnia: A randomized controlled trial and direct comparison. Archives of Internal Medicine. 2004;164(17):1888-1896. doi:10.1001/archinte.164.1 $\underline{7.1888}$

16. Omvik S, Sivertsen B, Pallesen S, Bjorvatn B, Havik OE, Nordhus IH. Daytime functioning in older patients suffering from chronic insomnia: Treatment outcome in a randomized controlled trial comparing CBT with Zopiclone. Behaviour Research and Therapy. 2008;46(5):623-641. doi:10.1016/j.brat.2008.02.013

17. McClusky HY, Milby JB, Switzer PK, Williams V, Wooten V. Efficacy of behavioral versus triazolam treatment in persistent sleep-onset insomnia. American Journal of Psychiatry. 1991;148(1):121-126. $\underline{\mathrm{d}}$ oi:10.1176/ajp.148.1.121

18. Hintze JP, Edinger JD. Hypnotic discontinuation in chronic insomnia. Sleep Medicine Clinics. 2018;13(2):263-270. doi:10.1016/i.jsmc.2018.02.008

19. Roth T, Krystal A, Steinberg FJ, Singh NN, Moline M. Novel sublingual low-dose zolpidem tablet reduces latency to sleep onset following spontaneous middleof-the-night awakening in insomnia in a randomized, double-blind, placebo-controlled, outpatient study. Sleep. 2013;36(2):189-196. doi:10.5665/sleep.2370

20. Herring WJ, Snyder E, Budd K, et al. Orexin receptor antagonism for treatment of insomnia: A randomized clinical trial of suvorexant. Neurology. 2012;79(23):2265-2274. doi:10.1212/WNL.0b013e318 27688ee

21. Ferracioli-Oda E, Qawasmi A, Bloch MH. MetaAnalysis: Melatonin for the Treatment of Primary Sleep Disorders. PLoS ONE. 2013;8(5):63773. doi:10.1 371/journal.pone.0063773 
22. Zolpidem Uses, Dosage \& Side Effects Drugs.com.

23. FDA. Zolpidem Prescribing and Safety Information. Published 2007. Accessed October 11, 2020. https://www.accessdata.fda.gov/drugsatfda_doc s/label/2008/019908s027lbl.pdf

24. Sanger DJ, Depoortere H. The Pharmacology and Mechanism of Action of Zolpidem. CNS Drug Reviews. 1998;4(4):323-340. doi:10.1111/i.1527-3458.1998.tb0 $\underline{0074 . \mathrm{X}}$

25. PubChem Compound Summary for CID 5732, Zolpidem. National Center for Biotechnology Information.

26. Drover D, Lemmens H, Naidu S, Cevallos W, Darwish M, Stanski D. Pharmacokinetics, pharmacodynamics, and relative pharmacokinetic/ pharmacodynamic profiles of zaleplon and zolpidem. Clinical Therapeutics. Published online 2000. doi:10.1 016/S0149-2918(00)83043-X

27. Salvà $\mathrm{P}$, Costa J. Clinical Pharmacokinetics and Pharmacodynamics of Zolpidem. Clinical Pharmacokinetics. Published online 1995. doi:10.2165/ 00003088-199529030-00002

28. Byeon JY, Kim YH, Kim SH, et al. The influences of CYP2C $9 * 1 / * 3$ genotype on the pharmacokinetics of zolpidem. Archives of Pharmacal Research. Published online 2018. doi:10.1007/s12272-018-1070-y

29. Olubodun JO, Ochs HR, Von Moltke LL, et al. Pharmacokinetic properties of zolpidem in elderly and young adults: Possible modulation by testosterone in men. British Journal of Clinical Pharmacology. Published online 2003. doi:10.1046/j.0 306-5251.2003.01852.x

30. Westermeyer J, Carr TM. Zolpidem-associated consequences: An updated literature review with case reports. Journal of Nervous and Mental Disease. 2020;208(1):28-32. doi:10.1097/NMD.0000000000001 $\underline{074}$

31. Gillis CM, Poyant JO, Degrado JR, Ye L, Anger KE, Owens RL. Inpatient pharmacological sleep aid utilization is common at a tertiary medical center. Journal of Hospital Medicine. 2014;9(10):652-657. do i:10.1002/jhm.2246

32. Park SM, Ryu J, Lee DR, Shin D, Yun JM, Lee J. Zolpidem use and risk of fractures: a systematic review and meta-analysis. Osteoporosis International. 2016;27(10):2935-2944. doi:10.1007/s00198-016-360 $\underline{5-8}$
33. Treves N, Perlman A, Geron LK, Asaly A, Matok I. $\mathrm{Z}$-drugs and risk for falls and fractures in older adults-a systematic review and meta-analysis. Age and Ageing. 2018;47(2):201-208. doi:10.1093/ageing/a $\underline{\mathrm{fx} 167}$

34. Andrade C. Sedative hypnotics and the risk of falls and fractures in the elderly. Journal of Clinical Psychiatry. 2018;79(3). doi:10.4088/JCP.18f12340

35. Stranks EK, Crowe SF. The acute cognitive effects of zopiclone, zolpidem, zaleplon, and eszopiclone: A systematic review and meta-analysis. Journal of Clinical and Experimental Neuropsychology. 2014;36(7):691-700. doi:10.1080/13803395.2014.9282 $\underline{68}$

36. Ito SU, Kanbayashi T, Takemura T, et al. Acute effects of zolpidem on daytime alertness, psychomotor and physical performance. Neuroscience Research. 2007;59(3):309-313. doi:10.1016/i.neures.2 007.07.009

37. Mahoney JE, Webb MJ, Gray SL. Zolpidem prescribing and adverse drug reactions in hospitalized general medicine patients at a veterans affairs hospital. American Journal Geriatric Pharmacotherapy. 2004;2(1):66-74. doi:10.1016/S1543-5946(04)90008-6

38. Mcmahon M. Zolpidem, complex sleep-related behaviour and volition. Journal of Law, Medicine, and Ethics. 2016;24(2):455-477.

39. Australina Government Department of Health Therapeutic Goods Administration. Zolpidem ('Stilnox') | Therapeutic Goods Administration (TGA). Accessed October 11, 2020. https://www.tga.gov.au/al ert/zolpidem-stilnox

40. Wong CK, Marshall NS, Grunstein RR, et al. Spontaneous adverse event reports associated with zolpidem in the United States 2003-2012. Journal of Clinical Sleep Medicine. 2017;13(2):223-234. doi:10.56 64/jicsm.6452

41. Stallman HM, Kohler M, White J. Medication induced sleepwalking: A systematic review. Sleep Medicine Reviews. 2018;37:105-113. doi:10.1016/i.smr v.2017.01.005

42. Sun Y, Lin CC, Lu CJ, Hsu CY, Kao CH. Association between zolpidem and suicide: A nationwide population-based case-control study. Mayo Clinic Proceedings. 2016;91(3):308-315. doi:10.1016/j.mayoc p.2015.10.022 
43. Schifano F, Chiappini S, Corkery JM, Guirguis A. An insight into z-drug abuse and dependence: An examination of reports to the European medicines agency database of suspected adverse drug reactions. International Journal of Neuropsychopharmacology. 2019;22(4):270-277. doi:10.1093/ijnp/pyz007

44. Chiaro G, Castelnovo A, Bianco G, Maffei P, Manconi M. Severe chronic abuse of zolpidem in refractory insomnia. Journal of Clinical Sleep Medicine. 2018;14(7):1257-1259. doi:10.5664/jcsm.7240

45. Victorri-Vigneau C, Gérardin M, Rousselet M, Guerlais M, Grall-Bronnec M, Jolliet P. An update on zolpidem abuse and dependence. Journal of Addictive Diseases. 2014;33(1):15-23. doi:10.1080/10550887.201 $\underline{4.882725}$

46. Licata SC, Mashhoon Y, MacLean RR, Lukas SE. Modest abuse-related subjective effects of zolpidem in drug-naive volunteers. Behavioural Pharmacology. 2011;22(2):160-166. doi:10.1097/FBP.0b013e328343d $\underline{78 \mathrm{a}}$

47. Cubała WJ, Landowski J. Seizure following sudden zolpidem withdrawal. Progress in Neuro-

Psychopharmacology and Biological Psychiatry. 2007;31(2):539-540. doi:10.1016/i.pnpbp.2006.07.009

48. MacFarlane J, Morin CM, Montplaisir J. Hypnotics in insomnia: The experience of zolpidem. Clinical Therapeutics. 2014;36(11):1676-1701. doi:10.1016/j.cl inthera.2014.09.017
49. Farkas RH, Unger EF, Temple R. Zolpidem and driving impairment - Identifying persons at risk. New England Journal of Medicine. 2013;369(8):689-691. do i:10.1056/NEJMp1307972

50. Greenblatt DJ, Harmatz JS, Roth T. Zolpidem and gender: Are women really at risk? Journal of Clinical Psychopharmacology. 2019;39(3):189-199. doi:10.109 7/JCP.0000000000001026

51. Greenblatt DJ, Legangneux E, Harmatz JS, et al. Dynamics and kinetics of a modified-release formulation of zolpidem: Comparison with immediate-release standard zolpidem and placebo. Journal of Clinical Pharmacology. 2006;46(12):1469-1480. doi:10.1177/00912700062933 $\underline{03}$

52. Cubała WJ, Landowski J, Wichowicz HM. Zolpidem abuse, dependence and withdrawal syndrome: Sex as susceptibility factor for adverse effects. British Journal of Clinical Pharmacology. 2008;65(3):444-445. doi:10.1 111/i.1365-2125.2007.03028.x

53. Wang LH, Lin HC, Lin CC, Chen YH, Lin HC. Increased risk of adverse pregnancy outcomes in women receiving zolpidem during pregnancy. Clinical Pharmacology and Therapeutics. 2010;88(3):369-374. $\underline{\mathrm{d}}$ oi:10.1038/clpt.2010.97

54. Carberry JC, Fisher LP, Grunstein RR, et al. Role of common hypnotics on the phenotypic causes of obstructive sleep apnoea: Paradoxical effects of zolpidem. The European respiratory journal. 2017;50(6). doi:10.1183/13993003.01344-2017 